\title{
Modulation by CAMP of a Slowly Activating Potassium Channel Expressed in Xenopus Oocytes
}

\author{
Edward M. Blumenthal' ${ }^{1}$ and Leonard K. Kaczmarek ${ }^{1,2}$ \\ 'Interdepartmental Neuroscience Program and 'Departments of Pharmacology and Cellular and Molecular Physiology, \\ Yale University School of Medicine, New Haven, Connecticut 06510
}

\begin{abstract}
When expressed in the Xenopus oocyte, the minK protein induces a slowly activating voltage-dependent potassium current $\left(l_{\mathrm{sk}}\right)$. We studied the modulation of this current by altering intracellular CAMP levels and found that the amplitude of $I_{s k}$ is dramatically increased by treatments that raise CAMP levels and decreased by agents that lower CAMP levels. Preinjection of a protein inhibitor of the cAMP-dependent protein kinase blocked the effects of increased cAMP levels. There were no changes in the voltage dependence or kinetics of $I_{\mathrm{sk}}$. Mutations that eliminate a potential phosphorylation site on the minK protein did not block the effects of activating the kinase. In addition, the membrane capacitance of the oocyte increased and decreased in parallel with $l_{\mathrm{gk}}$. Our results fit a mechanism in which channel proteins are selectively inserted into and removed from the plasma membrane in response to changes in kinase activity.
\end{abstract}

Potassium channels play an important role in determining the firing pattern and the shape of action potentials in neurons and other excitable cells (Cook, 1990). In recent years, the genes coding for a number of different voltage-dependent polassium channels have been isolated. With one exception, the minK (minimal K) gene, all of the genes belong to the same extended family, which also includes the major subunits of the voltagedependent sodium and calcium channels (for reviews, see Jan and Jan, 1990; Kaczmarek, 1991). The predicted structures of the proteins encoded by these genes are organized into domains containing six proposed membrane-spanning helices and a number of other highly conserved motifs. In contrast, the minK protcin contains only 130 amino acids and one proposed hydrophobic transmembrane helix and has no homology with the other cloned ion channels (Takumi et al., 1988).

mRNA for the minK protein is expressed in a variety of tissues including estrogen-primed uterus, heart, and kidney proximal tubule (Folander et al., 1990; Pragnell et al., 1990; Sugimoto et al., 1990). When expressed in the oocytes of the clawed frog Xenopus laevis, RNA from $\min K$-expressing tissue or from the cloned gene induces a voltage-dependent potassium current $\left(I_{\mathrm{sk}}\right)$ that activates slowly over many seconds (Boyle et al., 1987; Takumi et al., 1988).

\footnotetext{
Received June 18, 1991; revised Aug. 19, 1991; accepted Aug. 26, 1991.

We thank Dr. R. Swanson for the human and mutant minK clones, Drs. S. Amara and R. Handschumacher for Xenopus laevis, and Todd Lubart for assistance with data analysis. This work was supported by NIH Grant HL38156 and a grant from the Cystic Fibrosis Foundation to L.K.K.

Correspondence should be addressed to Dr. Leonard Kaczmarek, Department of Pharmacology, Yale Medical School, 333 Cedar Street, New Haven, CT 06510. Copyright (C) 1992 Society for Neuroscience $0270-6474 / 92 / 120290-07 \$ 05.00 / 0$
}

The physiological role of the minK channel is not yet known, and speculations on its function are based solely upon its localization. Investigation of the factors that regulate $I_{\mathrm{sk}}$ may therefore help to clarify the role of the minK protein in situ.

We have now investigated the modulation of $I_{\mathrm{sk}}$ by the cAMPdependent protein kinase (PKA). Modulation by second messengers has been described for a number of different classes of potassium currents in their native cellular environment (Kaczmarek and Levitan, 1987). The Xenopus oocyte expression system is well suited for the study of such regulation since one can record currents caused by a single species of injected RNA (Dascal, 1987). Despite this, there has been only one recent report of the modulation of a cloned potassium channel expressed in oocytes (Hoger et al., 1991), and no studies of regulation by PKA. We now report that, despite the lack of any consensus phosphorylation sites on the minK protein, the current is dramatically modulated by changes in PKA activity.

\section{Materials and Methods}

In vitro transcription. The rat $\min K$ clone (Takumi et al., 1988; Pragnell et al., 1990) was in pGEM2 and was linearized with HindIII (Promega or Boehringer Mannheim). $K_{v} l$ and the human $\operatorname{minK}$ mutants (a gift of Dr. R. Swanson, Merck, Sharp and Dohme) were in pGEM-A [Swanson et al., 1990; a pGEM-9zf(-) vector with a built-in polyA tail] and were linearized with Not I (Promega or Boehringer Mannheim). Run-off transcripts were prepared in a reaction containing linearized template, reaction buffer (Promega), dithiothrcitol (Promcga; $10 \mathrm{~mm}$ ), rNTPs (Promega; $500 \mu \mathrm{M}$ each), RNasin (Promega; $1.5 \mathrm{U} / \mu \mathrm{l}), \mathrm{mG}\left(5^{\prime}\right) \mathrm{ppp}\left(5^{\prime}\right) \mathrm{Gm}$ (Pharmacia; $100 \mu \mathrm{M}$ ), and RNA polymerase [SP6 (Promega) or T7 (gift of Dr. T. Steitz, Yale University)]. The template was then digested with DNase (Promega), and the RNA was purified by multiple ethanol precipitations and dissolved in diethyl pyrocarbonate treated sterile water at either $0.2 \mathrm{mg} / \mathrm{ml}\left(\mathrm{K}_{\mathrm{v}} 1\right)$ or $0.05 \mathrm{mg} / \mathrm{ml}$ (others). The RNA was stored in small aliquots at $-70^{\circ} \mathrm{C}$.

Oocyte isolation and injection. Adult female Xenopus laevis (Nasco, Ft. Atkinson, WI) were anesthetized in ice-cold 0.2\% 3-aminobenzoic acid ethyl ester (Sigma). Ovarian lobes were removed through a slit in the abdominal wall, which was then sutured. Animals were not operated on more than once in any 2 week period and were occasionally injected with $500 \mathrm{U}$ gonadotrophin (Sigma) and left for at least 4 weeks to regenerate oocytes. The oocytes were separated by incubation at room temperature for $1.5-3 \mathrm{hr}$ with $2 \mathrm{mg} / \mathrm{ml}$ collagenase (Boehringer Mannheim) in calcium-free Ringer's solution [ $88 \mathrm{mM} \mathrm{NaCl}, 1 \mathrm{mM} \mathrm{KCl}, 2.4$ $\mathrm{mm} \mathrm{NaHCO}_{3}, 0.8 \mathrm{mM} \mathrm{MgSO}_{4}, 15 \mathrm{~mm}$ HEPES pH $\left.7.6(\mathrm{NaOH})\right]$. Following collagenase treatment, large healthy stage $\mathrm{V}$ and VI oocytes (Dumont, 1972) were transferred into $\mathrm{OR}_{3}[50 \% \mathrm{~L}-15$ (GIBCO), $15 \mathrm{~mm}$ HEPES pH 7.6, $50 \mu \mathrm{g} / \mathrm{ml}$ gentamycin (Sigma)]. After sitting at room temperature for $2-18 \mathrm{hr}$ to overnight, the oocytes were injected with 50 $\mathrm{nl}$ of RNA. The oocytes were incubated in $\mathrm{OR}_{3}$ at $19^{\circ} \mathrm{C}$ for $3 \mathrm{~d}$ and then moved to $14^{\circ} \mathrm{C}$. Electrophysiology was always performed at least $3 \mathrm{~d}$ after RNA injection.

For kinase inhibitor injection, oocytes were injected with $50 \mathrm{nl}$ of a buffer containing $5 \mathrm{~mm}$ 2-(N-morpholino)-ethanesulfonic acid (MES) (CalBiochem; $\mathrm{pH} 7.0$ ) and $1 \mathrm{mg} / \mathrm{ml} \mathrm{BSA} \mathrm{(Sigma)} \mathrm{with} \mathrm{or} \mathrm{without} \mathrm{the}$ 
kinase inhibitor (Walsh et al., 1971; gift of Dr. A. Nairn, Rockefeller University) at $1.6 \mathrm{mg} / \mathrm{ml}$. See Results for further details.

Electrophysiology. Oocyte membrane currents were recorded using standard two-electrode voltage-clamp procedures with a World Precision Instruments S-7100 voltage clamp controlled by a PDP-11/24 computer (Indec). The recording and analysis software was a modified version of bcLAmp (Indec). Electrodes were filled with $3 \mathrm{M} \mathrm{KCl}$ and had resistances of $0.2-1.5 \mathrm{M} \Omega$. The current signal was filtered at $500 \mathrm{~Hz}$, the time invariant leak current was subtracted, and both current and voltage records were digitized and stored on disk.

The recording solution was designed to minimize endogenous chloride currents (Barish, 1983; Boyle et al., 1987) and contained (in mM) $96 \mathrm{Na}$-aspartate, $2 \mathrm{~K}$-aspartate, $0.5 \mathrm{CaCl}_{2}, 5 \mathrm{MgCl}_{2}$, and $5 \mathrm{HEPES} \mathrm{pH}$ $7.6(\mathrm{NaOH})$. During $I_{\text {sk }}$ recording, the oocytes were briefly perfused before each pulse, as this seemed to give more consistent currents. All measurements of current were determined as the average of five pulses delivered every $15 \mathrm{sec}$. Except where noted, the holding potential was $-50 \mathrm{mV}$, command pulse was to $50 \mathrm{mV}$ for $1.5 \mathrm{sec}$, and currents were measured at the beginning of the tail current immediately following repolarization.

Membrane capacitance was measured by delivering a series of hyperpolarizing sawtooth voltage pulses, subtracting the estimated resistive current, and measuring the magnitude of the remaining capacitive current.

8-Br-cAMP (Sigma) was dissolved in recording solution at $1 \mathrm{~mm}$. Progesterone (Sigma) was stored as a $1 \mathrm{~mm}$ stock in ethanol at $-20^{\circ} \mathrm{C}$ and was diluted into recording solution immediately before use. Forskolin (CalBiochem) was stored as a $50 \mathrm{~mm}$ stock in ethanol at $4^{\circ} \mathrm{C}$ and was also diluted immediately before use.

\section{Results}

Modulation of $\mathrm{I}_{s k}$ by $c A M P$

Treatments that alter intracellular cAMP levels in the Xenopus oocytes change the amplitude of heterologously expressed $I_{\mathrm{sk}}$. We used the membrane-permeable analog 8-Br-cAMP (1 mM) to raise the cAMP levels. $I_{\mathrm{sk}}$ amplitude consistently began to increase within 3-5 min of drug addition and continued to increase for the remainder of the experiments $(n=9)$. The increase in current after about 15 min ranged from $16 \%$ to $144 \%$ (86 \pm $53 \%, \pm \mathrm{SD}$ ). In some oocytes, the current continued to increase to levels over fourfold greater than before drug treatment (Fig. $1 A$ ). We found only a weak correlation among the different injected oocytes between the final magnitudes of the current increase and the durations of 8 -Br-cAMP treatment. Treatment of uninjected oocytes with 8-Br-c $\Lambda$ MP had no consistent effects on the small endogenous outward currents (Fig. 1C).

In order to show that 8-Br-cAMP application was mimicking a rise in cAMP, we also investigated the effect of forskolin, an activator of adenylate cyclase. Forskolin $(50 \mu \mathrm{M})$ also induced a rapid increase in $I_{\text {sk }}$ amplitude in two oocytes (95\% and $67 \%$, respectively, within $35 \mathrm{~min}$ ).

The steroid hormone progesterone is the physiological trigger for meiotic maturation of Xenopus oocytes (reviewed in Maller, 1985). It has been shown to cause a transient decrease in intracellular cAMP levels (Cicirelli and Smith, 1985). We therefore studied the effect of $1 \mu \mathrm{M}$ progesterone on the amplitude of $I_{\mathrm{sk}}$. Consistent with its effects on cAMP levels, progesterone caused a decrease in $I_{\text {sk }}($ Fig. $1 B$ ). This effect began within $3 \mathrm{~min}$ and reached a maximum reduction of $43 \pm 9 \%(n=6) \quad 17-82 \mathrm{~min}$ after drug application.

A change in the amplitude of a current may result from a shift in the voltage dependence of the channels or, in the case of a very slowly activating current, a change in the kinetics of activation. We therefore analyzed these parameters for the action of 8-Br-cAMP on $I_{\text {sk }}$. Figure 2 shows plots of normalized current amplitude, measured at the end of a $1.5 \mathrm{sec}$ command pulse, as a function of command potential. Due to the slow kinetics

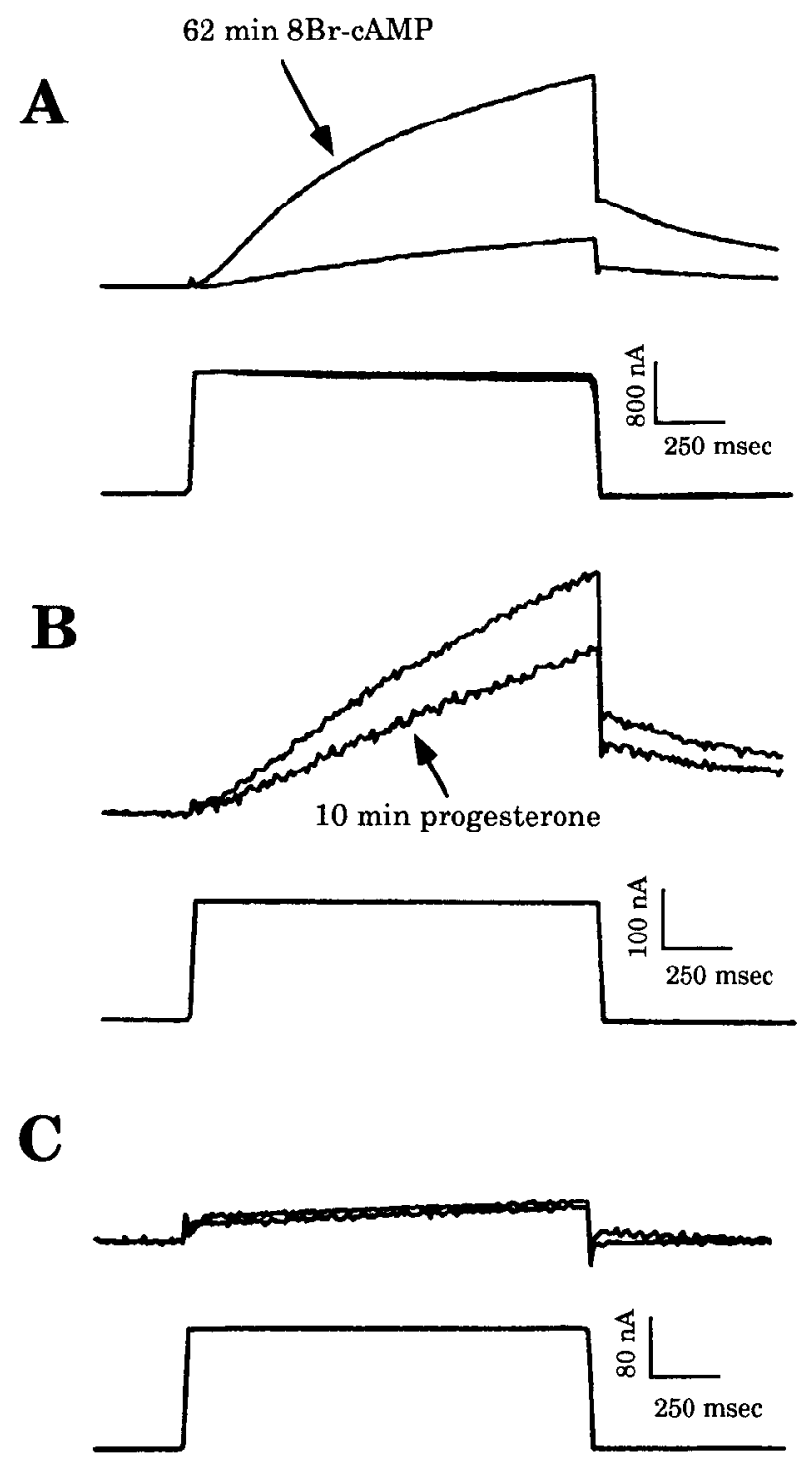

Figure 1. Changes in cAMP levels alter the magnitude of $I_{\text {sk }}$. All current traces are averages of five $1.5 \mathrm{sec}$ pulses from -50 to $50 \mathrm{mV}$. The pulses were delivered $15 \mathrm{sec}$ apart to allow for complete deactivation of $I_{\text {sk. }}$. $A$, Average traces before and $62 \mathrm{~min}$ after addition of $1 \mathrm{~mm} 8$-Br-cAMP. $B$, Average traces before and $10 \mathrm{~min}$ after addition of $1 \mu \mathrm{M}$ progesterone. $C, 8-\mathrm{Br}$-cAMP does not alter the endogenous currents of an uninjected oocyte. Average traces are before and $17 \mathrm{~min}$ after $1 \mathrm{~mm} 8$-Br-cAMP.

of $I_{\mathrm{sk}}$, such an isochronic plot could be sensitive to alterations in the activation kinetics. Nevertheless, there was no change in the voltage dependence following 8-Br-cAMP application. We also found no change in the reversal potential of the tail currents ( -92 to $-96 \mathrm{mV} ; n=3$; data not shown), indicating that there was no change in the selectivity of the current. Finally, we observed no consistent change in $I_{\mathrm{sk}}$ kinetics following any of the drug treatments. Thus, the effects of cAMP appeared to be strictly confined to current amplitude.

\section{Effects on capacitance}

In addition to the changes in $I_{\mathrm{sk}}$, we also observed changes in the capacitance of the oocyte plasma membrane $\left(C_{m}\right)$ in response to changes in cAMP levels. The membrane capacitance of Xenopus oocytes, which is a function of total surface area of the plasma membrane, is known to decrease in response to phorbol 


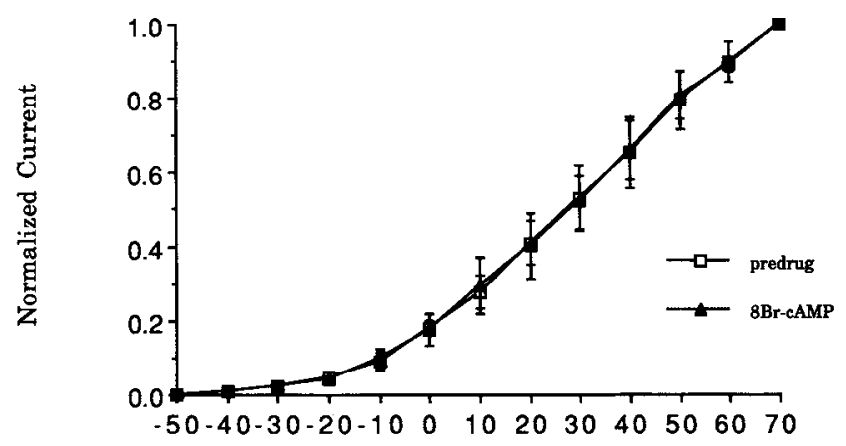

Command Potential
A

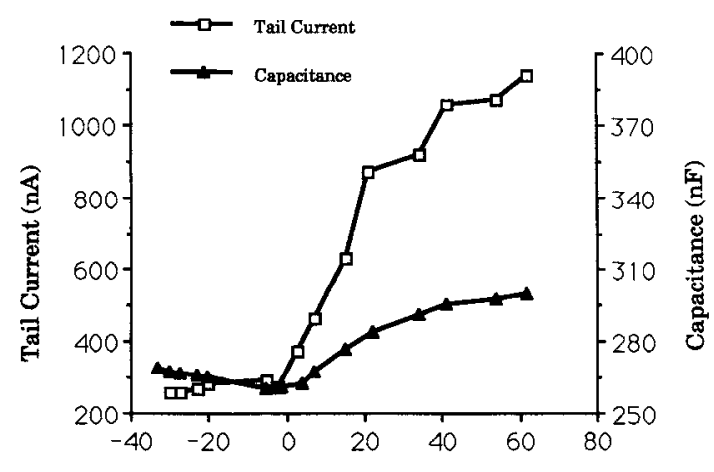

Time after 8Br-cAMP (min)

$\mathbf{B}$

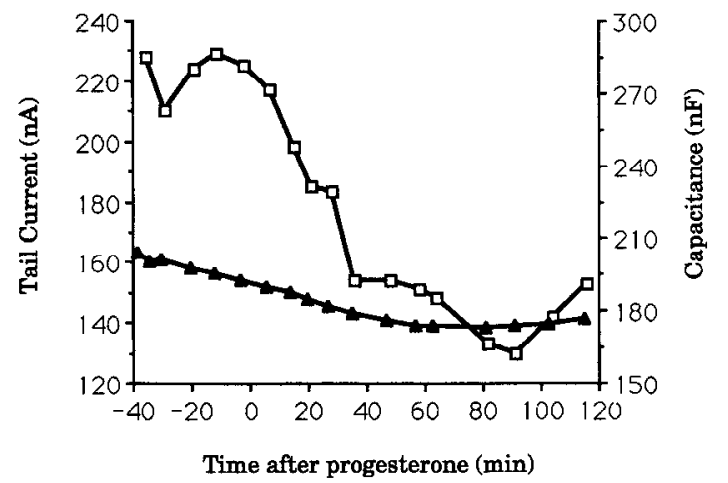

Figure 3. Time courses of the $8-\mathrm{Br}-\mathrm{cAMP}$ and progesterone effects. Typical time courses for the changes in $I_{\text {sk }}$ (squares) and capacitance (triangles) are shown. Tail currents were measured at $-50 \mathrm{mV}$ following a $1.5 \mathrm{sec}$ pulse to $50 \mathrm{mV}$. Drugs were added at time $0: A, 1 \mathrm{~mm} 8-\mathrm{Br}$ cAMP; $B, 1 \mu \mathrm{M}$ progesterone.

dent variability of $C_{m}$ in some oocytes, we feel that this result does not rule out PKA as the cause of the capacitance changes.

While conducting the inhibitor studies, we noticed that the baseline $I_{\text {sk }}$ amplitude was reduced in the inhibitor-injected oocytes compared with the controls. In order to test further the action of PKA on baseline $I_{\text {sk }}$, we compared oocytes that had been injected with either inhibitor or buffer and allowed to incubate overnight (10-13 hr). These data are summarized in Table 1. Although this treatment has been seen by others to induce oocyte maturation (Sadler and Maller, 1983), we did not consistently observe this effect. However, injection of PKA inhibitor caused a significant reduction in $I_{\mathrm{sk}}, C_{m}$, and current density $\left(I_{\mathrm{sk}} / C_{m}\right)$ relative to oocytes injected with buffer alone. In contrast, there were no differences in the resting potentials or input resistances between the two groups. Interestingly, the magnitudes of the $I_{\mathrm{sk}}$ and $C_{m}$ decreases (44\% and $11 \%$, respectively) were similar to those seen following progesterone treatment.

\section{Specificity of action of $C A M P$}

The effects of cAMP changes on $I_{\text {sk }}$ are not due to nonspecific endocytosis and exocytosis of oocyte plasma membrane. To show this, we coexpressed $I_{\text {sk }}$ with the delayed rectifier $\mathrm{K}_{\mathrm{v}} 1$, a mammalian member of the Shaker family (Swanson et al., 1990). $\mathrm{K}_{\mathrm{v}}$, when expressed alone, was not affected by either progesterone or 8-Br-cAMP (Fig. $5 A, B$ ). In coinjected oocytes, $I_{\mathrm{sk}}$ was selectively modulated by both progesterone and 8 -Br-cAMP (Fig. 5C,D). 
$\mathbf{A}$

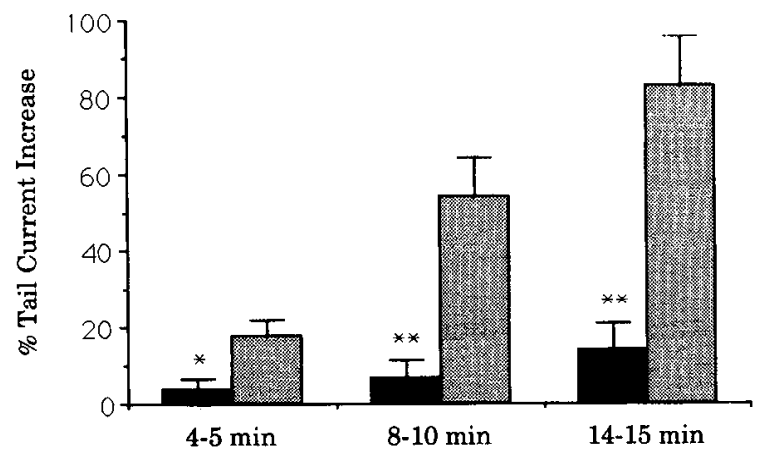

Time After 8Br-cAMP Addition

$\mathbf{B}$

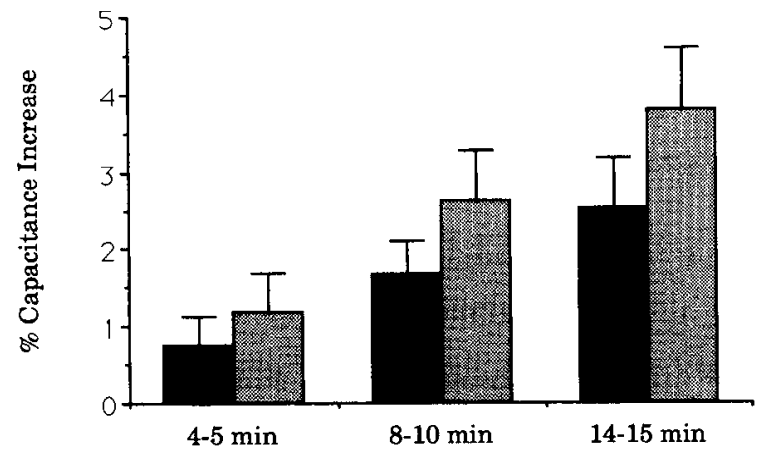

Time After 8Br-cAMP Addition

Figure 4. Effect of PKA inhibitor injection on the changes in current and capacitance. Oocytes were injected with either the inhibitor of PKA (solid bars) or buffer (shaded bars). After 2-6 hr, the oocytes were voltage clamped and treated with $1 \mathrm{~mm} 8$-Br-cAMP. Tail currents were measured at $-50 \mathrm{mV}$ after a $1.5 \mathrm{sec}$ pulse to $50 \mathrm{mV}$. The graphs show the percentage increases in tail current $(A)$ and capacitance $(B)$ relative to the values immediately before addition of 8 - $\mathrm{Br}-\mathrm{cAMP}(n=6$ oocytes). Error bars represent SEs. Currents in inhibitor-injected oocytes increased significantly less than in controls, two-tailed $t$ test: ${ }^{*} p<0.05$, ${ }^{* *} p<0.005$. Injection of inhibitor did not significantly attenuate the capacitance increases: $0.15>p>0.10$, one-tailed $t$ test, for last two time points.

\section{Regulation of minK mutants}

One potential mechanism for the increases in $I_{\text {sk }}$ after activation of PKA is direct phosphorylation of the minK channel protein. $\Lambda$ though this protein does not contain a classical consensus site for phosphorylation by PKA (R/K-R/K-X-S/T) (Krebs and Beavo, 1979), it does have one serine that is flanked by basic residues, a motif frequently found to be phosphorylated by protein kinases. We examined site-directed mutants of the human minK protein in which this putative phosphorylation site was altered (Table 2) (Murai et al., 1989). Expression of these mutants results in currents with slightly altered kinetics and voltage dependence (data not shown). Nevertheless, the currents from all three mutants, as well as the wild-type human current, increased in response to 8-Br-cAMP ( $n=2$ for each) (Fig. 6). These increases were similar in magnitude and time course to the rat $I_{\text {sk }}$ results. We conclude that the putative phosphorylation site is not necessary for modulation of $I_{\text {sk }}$ by PKA.

\section{Discussion}

We have shown that changes in the level of intracellular cAMP produce changes in the magnitude of $I_{\mathrm{sk}}$ expressed in Xenopus
Table 1. Inhibition of PKA affects baseline $I_{\mathrm{sk}}$ and $C_{\mathrm{m}}$

\begin{tabular}{lcc} 
& Oocyte & \\
\cline { 2 - 3 } Property & Buffer-injected & $\begin{array}{l}\text { Inhibitor- } \\
\text { injected }\end{array}$ \\
\hline Tail current $(\mathrm{nA})$ & $248 \pm 63$ & $139 \pm 67^{* *}$ \\
Capacitance $(\mathrm{nF})$ & $292 \pm 10$ & $260 \pm 12^{* *}$ \\
Current density $(\mathrm{nA} / \mathrm{nF})$ & $0.85 \pm 0.22$ & $0.54 \pm 0.26^{*}$ \\
Resting potential $(\mathrm{mV})$ & $-46 \pm 2$ & $-41 \pm 6$ \\
Input resistance $(\mathrm{M} \Omega)$ & $0.9 \pm 0.2$ & $1.1+0.4$
\end{tabular}

Data show properties of oocytes injected with either the PKA inhibitor $(n=7)$ or buffer $(n=9)$ and allowed to incubate overnight at $14^{\circ} \mathrm{C}$. Values are given as average $\pm \mathrm{SD}$. Inhibitor-injected differs from control, two-tailed t test: ${ }^{*} p<0.05$, $* * p<0.01$.

laevis oocytes. This modulation is due to changes in the activity of PKA. Treatments that increased PKA activity led to substantial increases in $I_{\mathrm{sk}}$ amplitude, while inhibition of the kinase caused the current to decrease. Modulation occurred over a relatively slow time course, tens of minutes, although a similar time course has been reported for modulation by forskolin of a heart calcium current expressed in oocytes (Dascal et al., 1986). The voltage dependence, ionic selectivity, and kinetics of $I_{\text {sk }}$ were unaffected by manipulation of cAMP. We also found that, in addition to its effects on currents, changing the activity of PKA altered cell capacitance, a sensitive measure of membrane surface area. Activation of the kinase caused a net addition of membrane to the surface of the oocyte, while inhibition of the kinase led to a net endocytosis.

There are two general mechanisms for the modulation of ion channels that may bring about an increase in current amplitude. The first is modification of channels that are already in the plasma membrane. The second is a change in the number of channels physically present in the membrane. Although our data do not definitely distinguish between the two alternatives, they are generally more consistent with the second possibility.

For the first mechanism, the $\operatorname{minK}$ protein would have to exist in two states-active and inactive-which could be interconverted through the action of PKA. Since cAMP does not alter kinetics or voltage dependence, the inactive state would have to be completely silent, making this scheme different from another two-state model of channel modulation, the "willing/ reluctant" model for the modulation of calcium channels by norepinephrine in dorsal root ganglion neurons (Bean, 1989). As stated earlier, there are no PKA consensus phosphorylation sites on the minK protein, and we have shown that deletion of the only likely phosphorylation site did not eliminate the PKA effect. Therefore, the conversion of minK from the inactive to the active conformation would have to involve either phos-

Table 2. Amino acid sequences of the human minK mutants

\begin{tabular}{ll} 
Protein & Sequence \\
\hline Wild type & -Ile-Arg-Ser-Lys-Lys- \\
Mutant 1 & -Ile-Arg-Ala-Lys-Lys- \\
Mutant 2 & -Ile-Gln-Ser-Lys-Lys- \\
Mutant 3 & -lle-Arg-Ser-Gln-Gln-
\end{tabular}

This sequence lies in the proposed cytoplasmic domain of the protein between residues 66 and 70 (Murai et al., 1989). 
Figure 5. Changes in cAMP levels do

$\mathbf{A}$
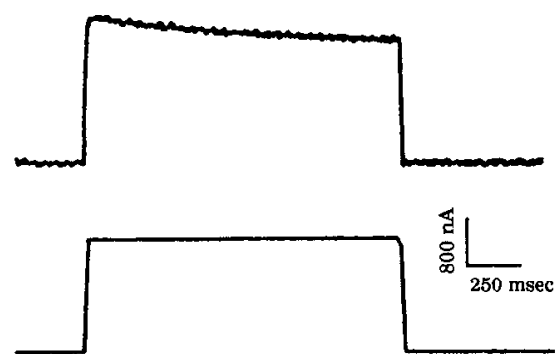

not affect the delayed rectifier $\mathrm{K}_{\mathrm{v}} 1 . A$ and $B$, Oocytes expressing $\mathrm{K}_{\mathrm{y}} 1$ alone. Traces were taken before and $13 \mathrm{~min}$ after 8-BrcAMP $(A)$ and before and 24 min after progesterone $(B)$. The pulse protocol was as in Figure 1, except that the holding potential was $-80 \mathrm{mV}$. C and $D$, Oocytes coexpressing $\mathrm{K}_{\mathrm{v}} 1$ and $I_{\mathrm{sk}}$. On this time scale, the current at the beginning of the pulse represents only $K_{v} 1$ while the tail currents are only $I_{\mathrm{sk}}$. Traces were taken before and 29 min after 8-Br-cAMP $(C)$ and before and $58 \mathrm{~min}$ after progesterone $(D)$. The pulse protocol was as in Figure 1.

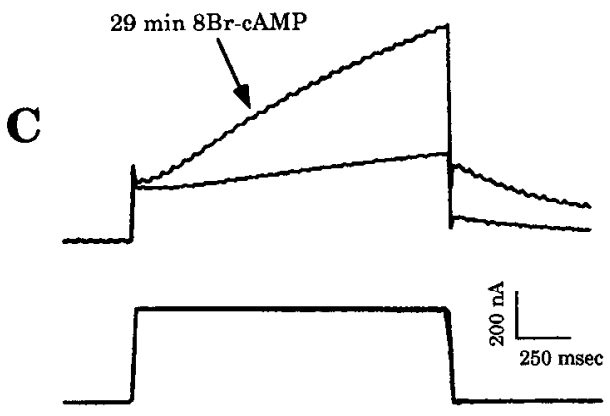

B

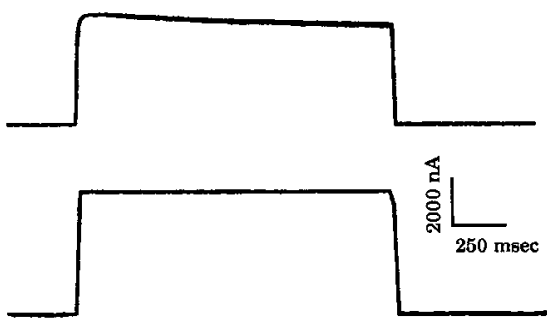

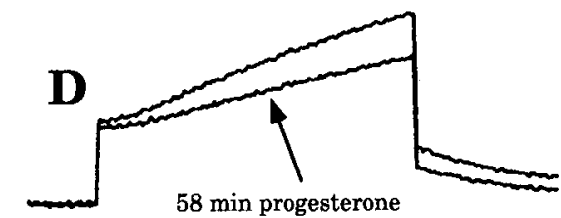

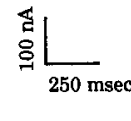

phorylation of minK by PKA at an "inhospitable" site, phosphorylation of minK by some other kinase, possibly due to the activation of a cascade of kinases, or phosphorylation of an associated endogenous oocyte protein.

The second possible mechanism for modulation of $I_{\mathrm{sk}}$ is a change in the amount of minK protein on the surface of the oocyte. In this scheme, changes in PKA activity would alter the kinetics of membrane trafficking to and from the surface of the oocyte. A number of assumptions are neccssary for this hypothesis to explain the data. First, the effect of PKA on membrane insertion would have to be specific to membranes containing the minK protein and/or any regulatory proteins for this channel. For example, the amplitude of the delayed rectifier $\mathrm{K}_{\mathrm{v}} 1$ did not change along with the capacitance. Furthermore, the changes in $I_{\mathrm{sk}}$ amplitude were always much larger than the changes in capacitance. Therefore, we would have to assume a specific population of vesicles, to which the minK protein is targeted, whose transport is regulated by PKA activity. There is evidence that such specific membrane trafficking exists in the oocyte. Progesterone has been shown to cause the rapid formation of large numbers of coated vesicles, apparently containing the progesterone receptors (Dersch et al., 1991). This observation is consistent with our observations of progesterone's effects on capacitance. Also, activation of protein kinase $\mathrm{C}$ causes a re-
$\mathbf{A}$

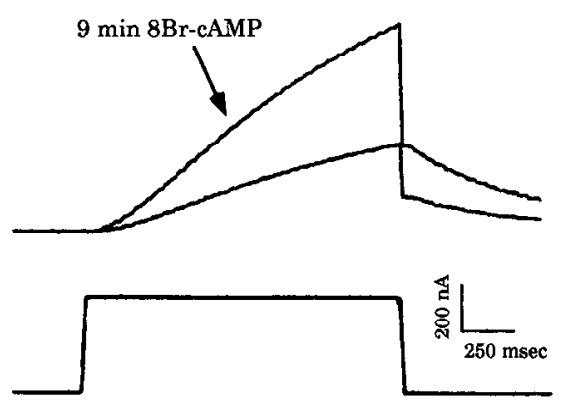

Figure 6. Alteration of a putative phosphorylation site does not eliminate the cAMP effect. $A$, The wild-type human $I_{\text {sk }}$ responds to 8-Br-cAMP in the same way as rat $I_{\mathrm{sk}}$. The pulse protocol was the same as in Figure 1. Traces were taken before and $9 \mathrm{~min}$ after drug addition. $B-D$, Pulses as above except that the command pulse was to $90 \mathrm{mV}$ to compensate for the altered voltage dependence of the mutants. Currents were measured before and within $10-15 \mathrm{~min}$ after addition of 8-Br-cAMP. $B$, mutant 1; $C$, mutant $2 ; D$, mutant 3 . See Table 2 for further details.

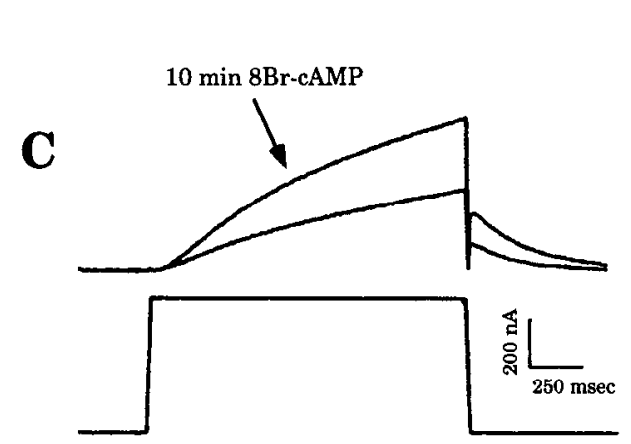

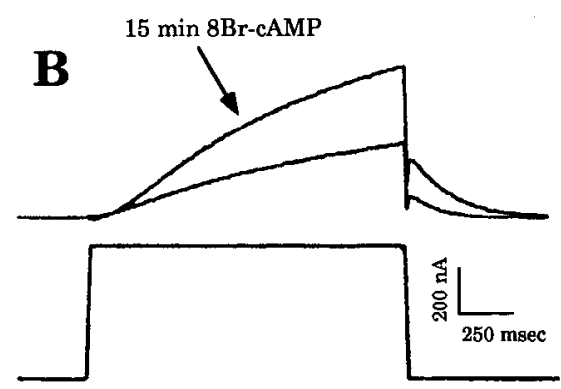

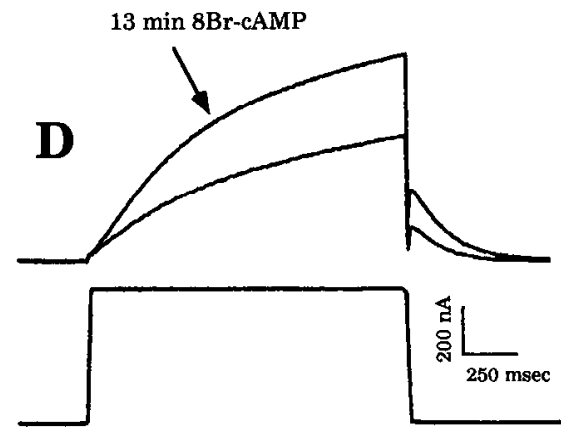


duction in the surface area of Xenopus oocytes that is associated with the selective endocytosis of the $\mathrm{Na}^{+} / \mathrm{K}^{+}$-ATPase (Vasilets et al., 1990). Finally, a subset of ion channels is selectively removed from the membrane during the maturation of starfish oocytes (Moody and Bosma, 1985).

One potential problem with this second mechanism is the weak correlation between total changes in $I_{\mathrm{sk}}$ and $C_{m}$ in different oocytes. It must be emphasized, however, that very few oocytes had absolutely stable baseline capacitances. It was far more common for the capacitance to vary with time, making calculations of capacitance changes inexact. The weak correlation could also be explained by assuming that the capacitance increase is due to the exocytosis of different classes of vesicles, of which only a specific subset contains the minK protein. The second, addition/subtraction mechanism more convincingly explains the lack of changes in the kinetics and voltage dependence following activation of PKA as well as the relatively slow time course of the changes in current. It is also consistent with the known ability of the oocyte to remove some proteins selectively from its surface.

Although the physiological role of the minK channel is not yet understood, there is evidence that cAMP-induced insertion and removal of plasma membrane containing ion channels occurs in the kidney, one of the tissues in which the minK protein is found (Sugimoto et al., 1990). In the principal cells of the collecting duct, vasopressin, which causes increases in cAMP, stimulates the delivery of water channels to the apical membrane (for review, see Brown, 1989). Moreover, parathyroid hormone, which elevates cAMP levels in cultured distal tubule epithelia, causes the appearance of L-type calcium channels in the cell membrane (Bacskai and Friedman, 1990). This process is dependent on a functional exocytotic apparatus.

The $\min K$ gene is also expressed in cardiac muscle (Folander et al., 1990). An examination of the potassium currents found in the heart suggests a possible role for $I_{\mathrm{sk}}$. The delayed rectifier of guinea pig ventricular myocytes is composed of different potassium currents, the largest and slowest of which, $I_{\mathrm{Ks}}$, has kinetics and voltage dependence similar to that of $I_{\mathrm{sk}}$ (Sanguinetti and Jurkiewicz, 1990). In addition, this current increases in response to activation of PKA (Bennett et al., 1986; Sanguinetti et al., 1991). Walsh and Kass (1988) have shown that although PKA activation increases both the calcium current and the delayed rectifier, the two currents seem to increase by different mechanisms. The change in the delayed rectifier is highly temperature dependent, while modulation of $I_{\mathrm{Ca}}$ is not. It is interesting to speculate that the modulation of this $I_{\mathrm{sk}}$-like potassium current might be due to exocytosis of a specific population of vesicles. Insertion and removal of channels could prove to be a widespread mechanism for cell-type-specific modulation of ionic currents.

\section{References}

Bacskai BJ, Friedman PA (1990) Activation of latent $\mathrm{Ca}^{2+}$ channels in renal epithelial cells by parathyroid hormone. Nature $347: 388-$ 391.

Barish ME (1983) A transient calcium-dependent chloride current in the immature Xenopus oocyte. J Physiol (Lond) 342:309-325.

Bean BP (1989) Neurotransmitter inhibition of neuronal calcium currents by changes in channel voltage dependence. Nature 340:153156.

Bennett P, McKinney L, Begenisich T, Kass RS (1986) Adrenergic modulation of the delayed rectifier potassium channel in calf cardiac Purkinje fibers. Biophys J 49:839-848.
Boyle MB, Azhderian EM, MacLusky NJ, Naftolin F, Kaczmarek LK (1987) Xenopus oocytes injected with rat uterine RNA express very slowly activating potassium currents. Science 235:1221-1224.

Brown D (1989) Membrane recycling and epithelial cell function. Am J Physiol 256:F1-F12.

Circirelli MF, Smith LD (1985) Cyclic AMP levels during the maturation of Xenopus oocytes. Dev Biol 108:254-258.

Cook NS ed (1990) Potassium channels: structure, classification, function, and therapeutic potential. Chichester: Horwood.

Dascal N (1987) The use of Xenopus oocytes for the study of ion channels. CRC Crit Rev Biochem 22:317-387.

Dascal N, Snutch TP, Lubbert H, Davidson N, Lester HA (1986) Expression and modulation of voltage-gated calcium channels after RNA injection in Xenopus oocytes. Science 231:1147-1150.

Dersch MA, Bement WM, Larabell CA, Mecca MD, Capco DG (1991) Cortical membrane-trafficking during the meiotic resumption of Xenopus laevis oocytes. Cell Tissue Res 263:375-383.

DiFrancesco D, Tortora P (1991) Direct activation of cardiac pacemaker channels by intracellular cyclic AMP. Nature 351:145-147.

Dumont JN (1972) Oogenesis in Xenopus laevis (Daudin). J Morphol 136:153-180.

Folander K, Smith JS, Antanavage J, Bennett C, Stein RB, Swanson R (1990) Cloning and expression of the delayed-rectifier $I_{\mathrm{sk}}$ channel from neonatal rat heart and diethylstilbestrol-primed rat uterus. Proc Natl Acad Sci USA 87:2975-2979.

Hoger JH, Walter AE, Vance D, Yu L, Lester HA, Davidson N (1991) Modulation of a cloned mouse brain potassium channel. Neuron 6: 227-236.

Jan LY, Jan YN (1990) How might the diversity of potassium channels be generated? Trends Neurosci 13:415-419.

Kaczmarek LK (1991) Voltage-dependent potassium channels: $\min K$ and Shaker families. New Biol 3:315-323.

Kaczmarek LK, Levitan IB (1987) Neuromodulation: the biochemical control of neuronal excitability. New York: Oxford UP.

Kado RT, Marcher K, Ozon R (1981) Electrical membrane properties of the Xenopus laevis oocyte during progesterone-induced meiotic maturation. Dev Biol 84:471-476.

Krebs E, Beavo J (1979) Phosphorylation-dephosphorylation of enzymes. Annu Rev Biochem 48:923-959.

Maller JL (1985) Regulation of amphibian oocyte maturation. Cell Differ 16:211-221.

Moody WJ, Bosma MM (1985) Hormone-induced loss of surface membrane during maturation of starfish oocytes: differential effects on potassium and calcium channels. Dev Biol 112:396-404.

Murai T, Kakizuka A, Takumi T, Ohkubo H, Nakanishi S (1989) Molecular cloning and sequence analysis of human genomic DNA encoding a novel membrane protein which exhibits a slowly activating potassium channel activity. Biochem Biophys Res Commun 161:176181.

Pragnell M, Snay KJ, Trimmer JS, MacLusky NJ, Naftolin F, Kaczmarek LK, Boyle MB (1990) Estrogen induction of a small, putative $\mathrm{K}^{+}$ channel mRNA in rat uterus. Neuron 4:807-812.

Sadler SE, Maller JL (1983) The development of competence for meiotic maturation during oogenesis in Xenopus laevis. Dev Biol 98:165172.

Sanguinetti MC, Jurkiewicz NK (1990) Two components of cardiac delayed rectifier $\mathrm{K}^{+}$current: differential sensitivity to block by class III antiarrhythmic agents. J Gen Physiol 96:195-215.

Sanguinetti MC, Jurkiewicz NK, Scott A, Siegl PKS (1991) Isoproterenol antagonizes prolongation of refractory period by the class III antiarrhythmic agent E-4031 in guinea pig myocytes: mechanism of action. Circ Res 68:77-84.

Sugimoto T, Tanabe Y, Shigemoto R, Iwai M, Takumi T, Ohkubo H, Nakanishi S (1990) Immunohistochemical study of a rat membrane protein which induces a selective potassium permeation: its localization in the apical membrane portion of epithelial cells. J Membr Biol 113:39-47.

Swanson R, Marshall J, Smith JS, Williams JB, Boyle MB, Folander K, Luneau CJ, Antanavage J, Oliva C, Buhrow SA, Bennett C, Stein RB, Kaczmarek LK (1990) Cloning and cxpression of cDNA and genomic clones encoding three delayed rectifier potassium channels in rat brain. Neuron 4:929-939.

Takumi T, Ohkubo H, Nakanishi S (1988) Cloning of a membrane protein that induces a slow voltage-gated potassium current. Science 242:1042-1045. 
Vasilets LA, Schmalzing G, Madefessel K, Haase W, Schwarz W (1990) Activation of protein kinase $C$ by phorbol ester induces downregulation of the $\mathrm{Na}^{+} / \mathrm{K}^{+}$-ATPase in oocytes of Xenopus laevis. J Membr Biol 118:131-142.

Walsh DA, Ashby CD, Gonzalez C, Calkins D, Fischer EH, Krebs EG
(1971) Purification and characterization of a protein inhibitor of adenosine $3^{\prime}: 5^{\prime}$-monophosphate-dependent protein kinases. J Biol Chem 246:1977-1985.

Walsh KB, Kass RS (1988) Regulation of a heart potassium channel by protein kinase $A$ and $C$. Science 242:67-69. 